\title{
Information Security and the Theory of Unfaithful Information
}

\author{
Aizhan Pernebekovna Pernebekova, Beisenkulov Ayazbi Ahbergenovich \\ L. N. Gumilyov Eurasian National University, Astana, Republic of Kazakhstan \\ Email: pernebekova.aizhan@yandex.ru, Beisenkulov_aa@enu.kz
}

Received 16 June 2015; accepted 6 September 2015; published 9 September 2015

Copyright (C) 2015 by authors and Scientific Research Publishing Inc.

This work is licensed under the Creative Commons Attribution International License (CC BY). http://creativecommons.org/licenses/by/4.0/

c) (i) Open Access

\begin{abstract}
In this article, the theory of information security is written as a context of national security. Article is devoted to an actual problem of legal support of information security in the Republic of Kazakhstan. The author analyzes modern problems and threats of information security in the conditions of globalization and considers aspects of information security. This article focuses on issues of spreading harmful information, which negatively affects the psyche, behavior, health, society and destabilizes the government administration. The article makes the case for improving the legislation of the Republic of Kazakhstan in strengthening informational security of individuals, society, the state, and measures to prevent the destructive impact of harmful information.
\end{abstract}

\section{Keywords}

Harmful Information, Information Security, Negative Information

In the concept of information security in the Republic of Kazakhstan, the information security is considered in terms of technical, social and political aspects.

According to the concept, the technical aspect includes the protection of national information systems, information and telecommunication infrastructure from unauthorized access, use, disclosure, violation, changes, reading, inspection, recording or destruction to ensure the integrity, confidentiality and availability of information.

Social and political aspect of information security lies in protection of information space and media vehicles from the targeted negative information and organizational impact, which can impair the national interests of the Republic of Kazakhstan.

As Krutskih A. V. [1] exactly notes, "the influence of targeted information on the opponent (competitor, opponent) is as old as the hills. However, only now, thanks to the latest technology, it evolves from the individual information diversions and disinformation activities to completely formed way of international policy featuring massive and universal nature of the application." 
The fact that the information can have an impact on the consciousness and psyche of the man became clear not only in our days, it's also justified by a number of scientists involved in research of such an impact.

In the beginning of the third millennium when the informational society is being established, the information security is taking a leading role in the system of national security. Therefore, formation of one integrated information security policy and its terms of development require priority. Thus the aim of the article is to research political mechanisms of providing information security, and define conceptual basis and principles of information security. In the Address to the people of Kazakhstan "Prosperity, security and ever growing welfare of all the Kazakhstanis" national security is defined as a long-term priority and one of the main aspects of national security is information security. In his later Addresses and during Security board sessions, the president mentioned necessity of developing the system of terms on information security [2].

Information security is relatively a new term which appeared at the end of XX century. General information theory, notion of information security became the object of research from the mid of the last century, onrush of information technologies and quick involvement of the countries which have just recently turned their development path to catalyst power of developed countries, that is worldwide globalization process, strengthening the actuality of information security.

So, G. V. Grachev [3], H. Domozetov [4], I. K. Melnik [5] proved that the influence of the information has different directions on the person.

For example, the available information has an impact mainly on its user in such a way to induce him to extremely positive acts in the exercise of own rights and responsibilities. Accordingly harmful (destructive) information has the opposite effect on its owner or user.

The Constitution of the Republic of Kazakhstan establishes only general provisions of prohibiting the distribution of harmful information, on this basis we can conclude that harmful information is clearly equated to illegal information. For example the clause 3 of article 13 in the Law of the Republic of Kazakhstan "On mass media” issued on 23rd of July, 1999 constates the basis for stopping to issue or distribute mass media: disclosure of information constituting state secrets or other secrets protected by law, information dissemination, revealing the techniques and tactics of anti-terrorist operations during their implementation, promotion of narcotic drugs, psychotropic substances and precursors, propaganda or agitation of cult of cruelty and violence, social, racial, national, religious, class and tribal superiority, the transmission of radio, television programs, and pornographic and sexual-erotic film and video demonstration, use of media for breaching the pre election campaign, for execution of activities by foreigners, stateless persons, foreign legal bodies, interfering and (or) promoting the nominating or electing of candidates, political parties that nominate party list and achieving certain results in elections, campaigning while its prohibited, forcing to participate or not participate in the strike.

General information theory, notion of information security became the objects of research from the mid of the last century, onrush of information technologies and quick involvement of the countries which have just recently turned their development path to catalyst power of developed countries, that is worldwide globalization process, strengthening the actuality of information security. However it is worth mentioning of works of several Kazakhstani researchers who wrote about information policy.

Famous political scientist G. Zh. Ibrayeva scientifically justified role and position of mass media in conditions of forming democratic society in Kazakhstan. She also researched impact of mass media, media system establishment in the country, state unity saving in conditions of entering the world information space, saving of culture and mentality of Kazakhstan people to information security.

In his doctorate thesis Y. K. Aliyarov paid attention to aspects of international and legal framework of country's information security as well as to methodological issues of informational policy establishment in conditions of global informational support. Some suggestions of Y. K. Aliyarov were reflected in information security concept of the Republic of Kazakhstan.

Documents, analyzing ways of current legal acts, structural and functional methods act as a methodological basis of the article. Actuality of this article is related to factors and conditions established in society below:

First, dynamic development of information technologies which play significant role in political and economic, socio-cultural life of society and state demands high requirements of solving information security issues, it means dependence of national security form information security is going to raise.

Second, development of globalization process is aligned with economic factors in the country as well as with information process and conditions of entering world information space. In conditions of entering worldwide information space and formation of national security in our country information security should be considered as 
an essential and exigent part of external and internal policy.

Third, in economic structure of the Republic of Kazakhstan in conditions where sector of raw materials prevail issues of training specialists in this sphere, development of information and communication techniques, technologies which play an important role in information security require their thorough consideration.

Fourth, information expansion of developed countries is strengthening in conditions of world globalization, in its turn it impacts to social, cultural aspects and independence of the country. Therefore researching technical, technological, legal aspects of information security along with humanitarian issues always has been important.

And the reasons for their termination are propaganda or agitation of forced change of the constitutional structure, violation of integrity of the Republic of Kazakhstan, undermining of state security, war, propaganda of extremism or terrorism, publication and dissemination of information materials aimed at inciting ethnic and religious hatred (paragraph 4 of Article 13 of the Law of the Republic of Kazakhstan "On the mass media" dated 23 July 1999).

The definition of harmful information in the legal context for the first time was given by I. L. Bachilo. In her opinion, the harmful information its a such information "the dissemination or use of which entails the need to protect legal entities from its negative impact.” But this is not the only definition of harmful information. Others understand by this the massive information, i.e. that is not confidential which damage entities as a result of its use or disseminating. Note that the definitions of harmful information are generalized and without specifying. However I. Panarin attempted to define them concretely, and as an information that can negatively affect the human psyche he refers the information that creates negative character and specially selected negative facts of reality that may be transmitted on television and in newspapers, information flow to extract one thing from which is impossible.

If we uphold his view, then such programs as “The court is in session”, “Trial by Jury” which have purpose of legal propaganda also refer to the range of information with negative impact on the human psyche. This specification implies the creation of a special structure that would include psychologists and other professionals who adequately determine the content of the information for its harmfulness.

In any case the harmful information infringes on the legal rights and interests of individuals, society and the state. Therefore, the state should respond properly by taking measures of protection from harm and damage from such information.

Obviously, the information can be related to harmful because of its specific features, most of which are characterized by psychological qualities that affect the psyche of a person and as a consequence his behavior.

These features include: falsity (inaccuracy), incompleteness, misrepresentation; the causing or threating of harm to the legitimate interests and rights of the individual, society and the state, including a negative impact.In our opinion, false information in itself may not always be harmful. False information or misinformation means false signals, failure to inform (concealment), distortion. In addition, there are also paradisinforming (transfer of mental images or "game" of meanings) and met a disinforming (using of fabrications). False information will be harmful only if it has harmful content. If you put the information that the bank incurs losses and soon will go bankrupt, then depositors will likely take their money from the bank and that will cause damages to the bank. But the false information that the powder is the only means to remove any stain can unlikely cause harm. A stain can be removed, not so much clearly as we would like, but anyways.

Foreign legislation also does not contain a clear notion of hazard information, the definition is generalized or specific types of harmful information are listed. For example, in UK the law on obscene publications accordingly recognizes the publication and dissemination of obscene being illegal. However it is recognized for legal persons of marriageable age to possess or watch obscene content.

A. V. Minbaleev [6] lists the harmful information types:

-false (doubtful, incomplete, inaccurate, corrupted);

-propaganda of pornography, violence, cruelty;

-inciting social, racial, national or religious hatred, hostility and superiority;

-destructively influencing on the psyche of the people;

-information about the unhealthy goods and services with limited turnover;

-offences;

-harmful to the health, moral and spiritual development of children;

-improper advertising.

Although in our opinion it's not correct to derive unfair advertising as a separate type of harmful information, 
since it is included in the general concept of the false information. In addition, the propaganda of pornography, violence, cruelty is a part of information harmful to the health, moral and spiritual development of children.

In our view, today we with complete confidence should talk about the availability of such kind of information as imposed information too, which also has a negative impact on the human psyche and health.

Spamming is so relevant to Internet users that not only a fine and maximum 6 million dollars, but also an imprisonment of up to five years for spamming were set by US federal law in 2003. But this law rest responsibility on illegal spammers.

Companies officially registered in the United States are not threatened. Also it's impossible to stop the spam that comes from servers located outside the United States. Spamming is becoming sophisticated so that the installed anti-spam filters and special protection programs are not able to recognize spam. For example, the message comes from the alleged user with whom the person assertedly had conversations or they are friends on social networks.Therefore, it's not difficult for receiver to respond to such a message, in fact spam protection system is cracked by such a response to this message. For example in Hong Kong since 2007 a law establishing responsibility for spamming as a fine of 2 million Hong Kong dollars or 128 thousand dollars and imprisonment for five years. And if a malicious spam program was spread by spam, then penalty will not be limited in size and the deprivation of freedom will be prolonged to 10 years. Legislations of Austria and Italy contain regulation entitling user to claim for compensation from the sender of spam to the extent of 5000 euros in the case of spamming without his (her) consent.

Thus, the notion of false information expands due to the imposed information that becomes a subtype of false information.

Based on the abovementioned the classification of harmful information can be represented as follows:

-false information, incomplete, corrupted, inaccurate, also imposed;

-inciting social, racial, national or religious hatred, hostility and enmity;

-encroach on the honor, dignity , name and reputation (in the case of recognition it to be false and misleading);

-obscene;

-destructively affects not only on the human psyche, but also on health.

However, in Kazakhstan's legislation there are no clear criteria for determining harmful information, no any explanation of the "harmful information" concept, there is no provision on execution of an examination by its definition, also it does not contain any rule governing the mechanism for dissemination of this information.

In our opinion the harmful information is information about persons, objects, facts, events, phenomena and processes regardless of its format, including databases, databanks and other information resources in information systems, negatively affecting the vital interests of society, the state, and personality by changing it's mind, behavior and health.Furthermore, it is possible to distinguish between information and legal security of the person and the information-psychological security.

Information and legal security of the person is the protection of all rights relating to the admission to information, which in its turn includes seeking, receiving, possessing, transfer, distribution, copying, non-proliferation, the creation of information.

And information-psychological security of the person is the protection of person from harmful information.

We should take into account the fact that human consciousness and subconsciousness can be manipulated due to the effect of information. Undoubtedly, manipulation specifically aimed at harming can harm one person as well as indefinite group of people. Manipulation is possible in any sphere of human activity. In the religious sphere the manipulation is aimed at attracting new believers into a particular religious group, in which they became zombie obedient to their leaders directions.

Manipulation is also possible in the economic sphere, when imposing one commodity that characterize the features and qualities which are exaggerated in comparison with similar products. Manipulation is possible in the political sphere too, where errors of policy are exaggerated and there is no mention of the measures taken to address them. Undoubtedly, criminal manipulation is also dangerous.

Therefore, the information security of the person forms by protecting the information from threats and harm, by protecting the individual from harmful information.

Information security depends not only on the technical possibilities of such protection, but also on the individual and to what he (she) understands the problems of causing damage to the computer system, and information, and him(her)self.

Of course, the legal base must settle information security, but it will be heavier to protect information user from 
the use of harmful information only by technical, legal means and methods without focusing on the development of information culture of using information flows.

Until now the phrase "Who owns the information-owns the world" has not lost its signification and actuality. Indeed, the "intensification of information dependency of the person on the growing volume of information needs requires arranged and systematically organized information, including on accessing to information, creating effective mechanisms to protect people from "harmful information", to implement clear criteria for its determination, to develop regulations for examination on the definition of "harmful information".

Also we think that the spread of information should be controlled by government. This control does not mean censorship. Due to the fact that modern information technology allows disguise the real content of the information so that its users do not suspect a violation of their rights, special professional knowledge are required to determine the harmful information. In this regard, we propose to form a special organization as a part of an existing Joint committee of the Republic of Kazakhstan on coordination of activities in the field of informatization and providing of information security which would deal with problems of determining the harms of information from internet. Regulations on the work of this organization must be based on legal restrictions of the human rights of access to information.

Information is a good that is being successfully sold. Without proper information you can create problems for yourself in different spheres of life. And it's clear that information without legal support cannot become a positively organizing thing in society.

Apparently, the problem of determining the harmfulness of information has matured and requires its legislative solution. Since only comprehensive legal regulation of information security can guarantee stability and peace in society.

In general, information security is a feature of all social activities and information process that provides life and development of humanity, turns human life into developed humanistic and information civilization, helps to prevent and eliminate irrelevant problems of informational support [7]. It means that only in conditions of providing information security informatization process of society acting as a development source can turn human life into intellectual and humanistic feature on the basis of information usage [8].

It is known that information security is one of the main fields of national security of every country. Law "On the national security of the Republic of Kazakhstan": states "information security-defense state of state information resources and individual rights, society interests in information field".

Currently issues of providing information security are relevant not only to our country, but also to all developed countries. Information systems in different spheres of life and resource using experience are indicating various risks of losing information which lead to material and other expenses. Moreover reaching of full security of information is a very complicated issue.

It is known if state authorities who make decisions on important issues are not provided with full, genuine and on time information then making precise and reasonable decisions would be hard. Some time ago US president R. Nicholson said " 1 dollar spent for false information and outreach is more important than 10 dollars spent for making weapons". Industry of information editing reached global degree. Complex changes in modern day human society, technologies of data editing influence on significance of information security issues. For instance, according to foreign bibliography sources, at the end of 70's service type in gathering, editing and using of information reached $46 \%$ of product in US national turnover and made $53 \%$ of total salary sum [5]. Creation of "electronic" money (credit cards) caused money theft in big amounts. It is possible to find much information on data theft from editing systems of automated data in press and different sources, it demonstrates significance and actuality of mentioned issues.

Providing of information security contains of a set of terms' system on providing information security and its tools as well as its subjects. The system of terms on providing information security is mainly characterized by significance direction, aim, principles, implementation objects and methods [9].

The most important of providing information security is legal level. Set of arrangements directed to creating of non-tolerant view to people who violate information security and infringing of information security belong to this level. The most important thing in this level is to create mechanism of law issuing which can follow the progress of information technologies. For sure, predicting everything in advance and issue the law according to it is impossible. However process of law issuing should not be in arrears of development process of information technologies. Because it can lead to information security reduction. One of the requirements of legal level is to correspond each state standards on information technologies and information security with international stand- 
ards.

Since declaring our independence a lot of law and Presidential decrees, governmental orders on development of information technologies, information security, information defense, information relation were published. It starts with the main articles of the Republic of Kazakhstan on information security of state policy and regulated by laws “On national security”, “On state secrets”, “On informatization”, Presidential decrees, governmental orders, state programs and interstate documents. 22nd article on providing information security is considered in law “On national security of the Republic of Kazakhstan". In 7th March of 2004 article on "Providing security in communication sphere" was added to this law.

Law "On state secrets" defines legal basis and integrated system of protection of state secrets on providing national security for the benefit of the Republic of Kazakhstan, it regulates social relations which come out of referring the data to state secrets, secreting them, ruling them, protecting and disclosing these secrets. Definitions to the following notions are given in the law: "state secrets", "state secret", "confidential information", "secret sign", "data sources which are state secrets", "protection system of state secrets”.

Different information types which are considered as state secrets are shown by this law. For instance, in the following spheres different information types which are considered as state secrets of the Republic of Kazakhstan are given: information on military sphere in 11th article, information on economics, science and technique in 12th article, information of foreign political and economical fields in 13th article, information on intelligence, counterintelligence, strategic search services and etc. In addition arrangements of referring the data to state secrets, order of secreting the data sources which are state secrets, data and principles of secreting their sources, secrecy level of data and secrecy sign of data sources, data and disclosing their secret sources, providing with information that is devoted to integrated and other works, giving secret information to foreign countries, giving permission of secret information to authorities of the Republic of Kazakhstan, citizens, and foreigners, certificating ways of protection tools of state secrets are indicated in the law.

Security policy is formed on the basis of analyses about the exact threats, which are dangerous for informational systems of organization. After analyzing possible threats and identifying protection strategy, the programme maintaining the information security will be adopted. Resources will be divided and responsible people will be appointed and the progress control will be identified according to this programme.

In the Ph.D. thesis "The development strategy of information policy of the Republic of Kazakhstan during the transition period" by A. Sarsenbaev, the aspects of information security were classified as external and internal:

The external aspect of information security is the necessity of organizing protection from the corrupted, false, aggressive and other external data, which affect negatively on the internal stability of a country, social and political processes and national identity. Keeping country's information security is that the government has rights to protect its national informational space from the external danger according to the interests of society and government.

The internal aspect of information security is to protect informational space against internal information which run counter to the national security, territorial integrity of a country, independence and interests of citizenry. The formation of the national informational system competitive with informational systems of other countries, preventive measures of national channels from external "attacks" are also considered as the internal informational system.

Currently, different types of mass media, also research papers, symposiums and conferences are mentioning the globalization process about which the whole world concerned.

Globalization is to attract the whole world to open system of financial and economic, socio-political and cultural relations using the advanced technology and informational space. This is an objective process, and now it accelerated [1]. Informatization of the world gives an opportunity to increase the role of non-governmental structures along with traditional players of international relations, governments. In our modern society, the new field, i.e. information sphere is coming out on top. Information sphere differentiates with the new contradictions formed in the result of fight directed to information and to acquirement of information as a new resource. Because of that, new threats related to the cyber security are appeared. In this case, there will be formed new view point to the notion "national security" as the most important function of government. In the case of globalization, also the notion "military force" will be changed, and the importance of information weapon increases compared to old traditional weapon. The improvement of the role of information technology in the sphere of security led to the introduction of new concept like "information war" in the structure of army force on the part of west countries, especially the USA. 
The provided details are only one of examples related to economic, technical aspects of the information security. Regarding the social-spiritual security, it is a natural phenomenon to have adverse effects as well as benefits of overall IT penetration in out society as the process of accessing to the global information space develops. The influence of mass media culture surely may move away the national culture on the second place. Because we can often see in any types of mass media, also Internet network compared to the level of mass media many materials that are inappropriate for our culture, education, It is perfectly clean that different programs and movies propagandizing violence, war, pornography in newspapers, magazines, TV have bad influence on youngsters and teenagers. If some call it "weaponless war", some are calling as "informational war", "information battle". American experts listed the following ways of informational counter actions (informational war, informational weapon):

-control system warfare;

-informational-reconnaissance operations;

-electronic warfare;

-against hackers (computer crime);

-informational and psychological warfare;

-cybernetic warfare;

-network warfare (including the informational terrorism);

-economical-informational warfare [10].

Generally, the aim of informational war, which is the danger for every country now, is that certain country (union of countries) takes dominance on informational sphere, and influences on their enemies explicitly or implicitly using available information resources, control their actions. In this case, it requires huge material and intellectual inputs, and a lot of time to restore the defeated part.

The informational warfare isn't used by the defense forces, and aimed to military objects. Other government organs and organizations, industrial and commercial structures participate in the informational warfare, and conduct their informational operations effecting on the solution of a conflict that take place. Therefore, we can say that the informational warfare is the complex of measures and operations oriented to provide the informational superiority comparison with opponents, and conducted by defense forces and other organizations in the interest of state national security.

Nowadays, the rate and capital of informational business are growing fast compared to other business. People who were in time and gave "interesting" information are earning money. Therefore, particular information is given in different form, in different content and finally it will be unknown which of them is right and which of them is wrong. It is obvious that user is not always able to clarify the true facts of the matter. It violates the right of individual of getting true information and intellectual proprietary rights of the owners of information. In this case, international network Internet plays a significant role, it may be used as an instrument of influence which propagandizes international terrorism, international dissension and religious extremism because of its openness and accessibility. The spiritual life requires public ideology which was prepared taking into account the interests of several ethnic groups who live in a particular area, their cultural and historical traditions in order to prevent and deactivate threats of informational security. It is said that the clear measures of evaluating the dangers of information security, main advantages in this area and state policy may be stated on the base of such ideology.

Information security in Kazakhstan is actual in all areas of society. It is clear that development of the process of globalization is directly related to information process, conditions of introducing to the world information space together with economic factors in the country. Therefore information space and its participants such as state structure, mass media, social organizations, individual citizens play an important role in forming and praising national soul and national patriotism.

Results of the conducted investigations give opportunities to suggest in the following theoretical and practical directions:

- One of the main political mechanisms to provide with the information security is to improve acts of normative and legal system in accordance with the process of technology developments. Teaching, explaining, helping works should be conducted in the process of law adoption, not prohibition and deterrence. The law in use is generally directed to secure information resources and the right of state power together with the state interests in the information field. Free access to information which is defined with the constitution of citizens, also legal acts that regulate the rights of information security, are not enough. Therefore, it is necessary to make the laws, such as "Information and information security", "About separate information". It 
is also necessary to pay attention to appropriateness of laws, which are adopted, will be adopted, changed and completed, and other normative right acts in version written in the national speech and Russian language [11]-[14].

- It is necessary to provide citizens with the right to get information on the function of the government body, improve the system "electronic government" used in order to increase types of electronic services for people, government bodies participated in the system, social organizations and access of citizens to the information resources and the security of information resources. State power bodies which participate in the system and vertically directed connection in exchange of information between the people are established. There is the insufficiency of horizontal communication between government bodies. Also low level of openness in the local self-control bodies, bureaucratic corruption attempts, lack of professional specialists and low level of their wages are reasons of that there are no works devoted to the security of state secrets appropriate to their level in the field of "electronic administration" program and measures that are obligatory to do.

\section{References}

[1] Krutskih, A.V. (2004) War or Peace: International Aspects.... Scientific and Methodological Problems of Information Security (Collected Works). Moscow.

[2] New Ten-Grades-New Economic Development-New Opportunities of Kazakhstan. Message of President of the Republic of Kazakhstan N.A. Nazarbaev to peoples of Kazakhstan, Egemen Kazakhstan, 30 January 2010.

[3] Mazur, M. (1974) Quaity Theory of Information. Moscow, Mir 1974, Grachev G.

[4] Domozetov, H. (2000) Computerization and Problems of Human Health, Freedom and Development. Philosophical and Sociological Thought, No. 4.

[5] Melnikov, V. (1997) Information Security in Computer Systems. Moscow: Finances and Statistics; Electroinform, p. 368.

[6] Minbaleev, A.V. (2005) Harmful Information as an Object of Legal Relations. Actual Problems of Modern Law and Legal Education: Materials of Scientific and Practical Conference. Publishing House of University for the Humanities, Ekaterinburg.

[7] Baturin, Y.M. (1987) Right and Policy in Computer Sphere. Moscow: Science, p. 112.

[8] Stolyarov, N.V. (n.d.) Notion, Essence, Aims and Meaning of Information Security. http://www.sec4all.net/infoprot-zakl.html

[9] About the National Security of the Republic of Kazakhstan, 26 June, 1998 Low N 233. www.e.gov.kz

[10] Decree No. 174 of President of the Republic of Kazakhstan dated 14th of November, 2014. (On Approving the Concept of Information Security in the Republic of Kazakhstan until 2016)

[11] Lopatin, V.N. (2000) Information Security of Russia: Man. Society. State, Moscow.

[12] Melnik, I. (1999) Manipulation of Person: The Arrangement, Methods and Technologies of Information and Psychological Impact. Institute of Philosophy of RAS, Moscow.

[13] Law No. 178-IV of the Republic of Kazakhstan issued on 10th of July, 2009. (On Implementing Amendments and Additions to Certain Legislative Acts of the Republic of Kazakhstan on Problems of Information and Communication Networks. Kazakhstanskaya Pravda, 2009, July 22)

[14] Berdibayev, R.Sh. (2010) Political Mechanisms of Providing Information Security in the Republic of Kazakhstan: Dissertation of Candidate of Political Sciences, Almaty. 